\title{
Endoscopic closure of a colocutaneous fistula after placement of percutaneous endoscopic gastrostomy
}

A 16-year-old boy with a history of neurofibromatosis type 1 and malignant peripheral nerve sheath tumor under chemotherapy underwent percutaneous endoscopic gastrostomy (PEG) placement for dysphagia, anorexia, and malnutrition. After PEG placement, the button was confirmed to be within the stomach. The feeding tube was replaced 5 months later, with the patient presenting with persistent diarrhea and weight loss. Contrast study revealed a colocutaneous fistula, with contrast infused through the PEG appearing in the colon ( Fig. 1). The patient was referred to us for endoscopic closure ( $\vee$ Video 1 ).

A conventional colonoscope was advanced to the distal transverse colon, where the PEG tube balloon could be seen. After fulguration of the fistula edges with argon plasma ( $\mathbf{F i g . 2 a ) , ~ a ~}$ 14/6-mm over-the-scope clip (OTSC) was placed using suction. However, clip displacement occurred, with fistula persistence ( Fig. 2 b). A second 14/6-mm OTSC was placed after pulling the fistula

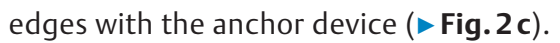
Despite correct OTSC placement, concern about possible incomplete apposition of the clips led us to place a detachable snare beneath the jaws of both OTSCs ( $\mathbf{F i g . 2} \mathbf{d}$ ), aided by a foreign body retrieval forceps advanced through the second working channel of a therapeutic gastroscope. Percutaneous stool leaking completely stopped 2 days later, confirming fistula closure.

Colocutaneous fistulas are rare complications of PEG placement, resulting from the interposition of the colon between the anterior abdominal and gastric walls. It is usually discovered after PEG replacement, as the tube is inserted into the colon and cannot be negotiated through the tract back into the stomach
[1]. With direct passage, diarrhea occurs immediately upon feeding when formula is instilled into the colon. Diagnosis can be confirmed radiographically [2]. Surgery used to be the mainstay for fistulas that fail to close; however, endoscopy may represent an effective and less invasive alternative.

Endoscopy_UCTN_Code_CPL_1AH_2AI

\section{Competing interests}

None

The authors

Eduardo Rodrigues-Pinto, Ana L. Santos, Guilherme Macedo

Gastroenterology Department, Centro Hospitalar São João, Porto, Portugal

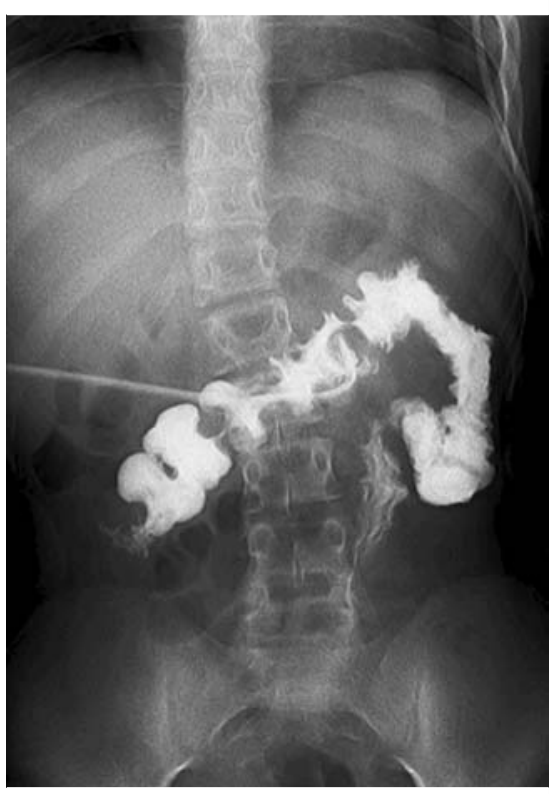

- Fig. 1 Contrast study revealing the colocutaneous fistula, with contrast that was infused through the percutaneous endoscopic gastrostomy appearing in the colon.

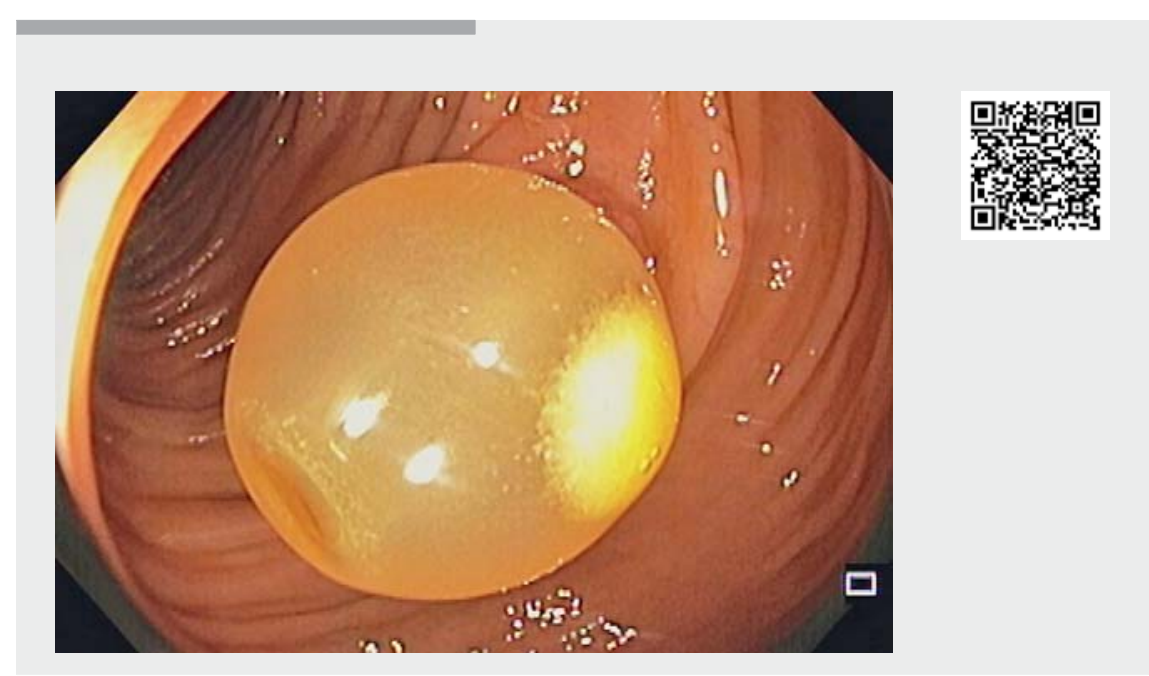

$\checkmark$ Video 1 Endoscopic closure of a colocutaneous fistula after percutaneous endoscopic gastrostomy placement. 

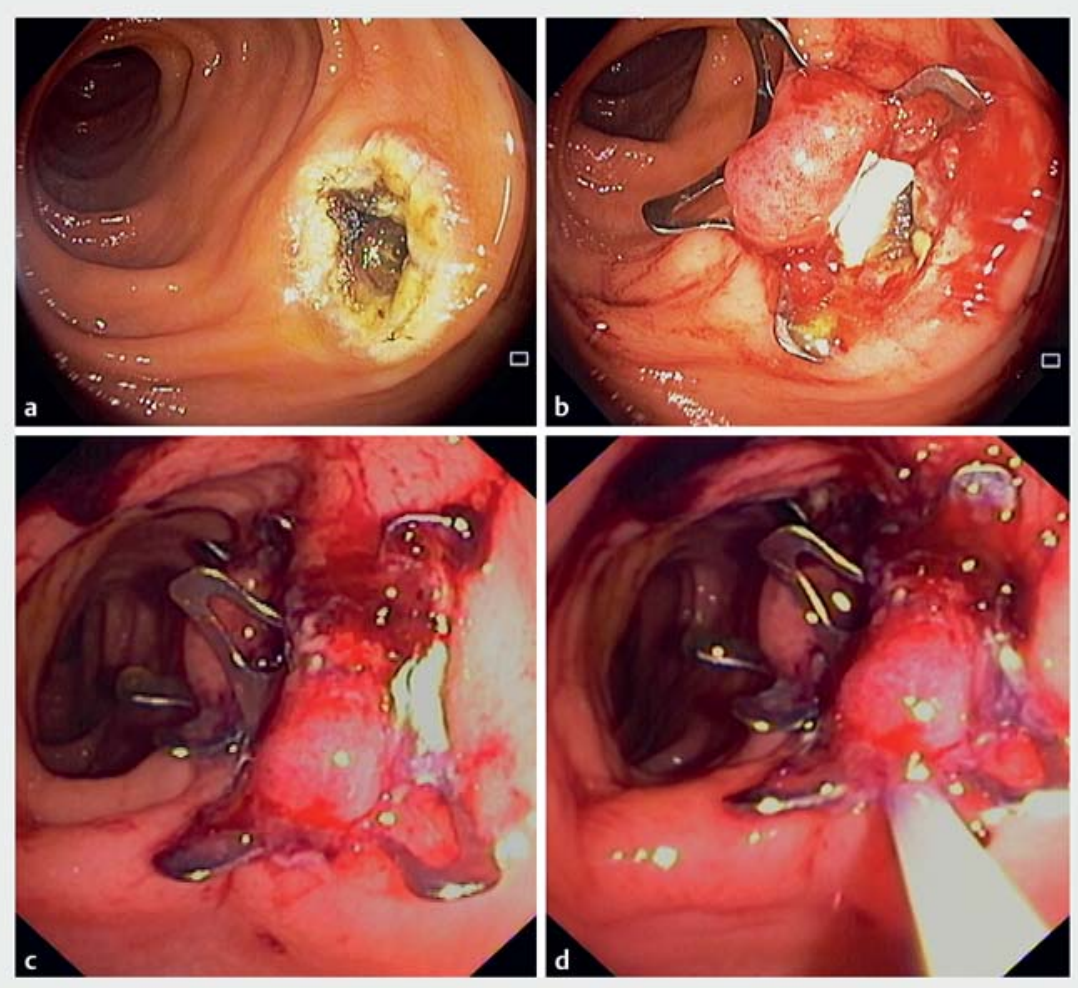

- Fig. 2 Endoscopic images. a The colocutaneous fistula after fulguration with argon plasma. b Placement of the first over-the-scope clip (OTSC), with fistula persistence. c Placement of the second OTSC, side-by-side with the first clip. $\mathbf{d}$ Placement of a detachable snare beneath both OTSCs.

\section{Corresponding author}

\section{Eduardo Rodrigues-Pinto, MD}

Gastroenterology Department, Centro Hospitalar São João, Alameda Prof. Hernâni Monteiro, 4200-319 Porto, Portugal

Fax: +351-22-5513601

edu.gil.pinto@gmail.com

\section{References}

[1] Emmett DS, Polter DE. Colocutaneous fistula after a PEG. Gastrointest Endosc 2008; 68: 770

[2] Lohiya GS, Tan-Figueroa L, Krishna V. Intermittent diarrhea as a delayed presentation of percutaneous endoscopic gastrostomy (PEG)-associated fistula. J Am Board Fam

\section{Bibliography}

DOI https://doi.org/10.1055/a-1063-6276

Published online: 9.12.2019

Endoscopy 2020; 52: E187-E188

(C) Georg Thieme Verlag KG

Stuttgart · New York

ISSN 0013-726X

\section{ENDOSCOPY E-VIDEOS \\ https://eref.thieme.de/e-videos}

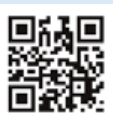

Endoscopy E-Videos is a free access online section, reporting on interesting cases and new

techniques in gastroenterological endoscopy. All papers include a high quality video and all contributions are freely accessible online.

This section has its own submission website at

https://mc.manuscriptcentral.com/e-videos Med 2010; 23: 681-684 